\title{
A Fuzzy PI Speed Controller based on Feedback Compensation Strategy for PMSM
}

\author{
Ou Sheng ${ }^{1}$, Liu Haishan ${ }^{2}$, Liu Guoying,Zeng \\ Guohui, Zhan Xing, Wang Qingzhen \\ School of Electronic and Electrical Engineering \\ Shanghai university of engineering science \\ Shanghai, China
}

\author{
Liu Haishan ${ }^{2}$ \\ School of Electronic and Electrical Engineering \\ Shanghai university of engineering science \\ Shanghai, China
}

\begin{abstract}
- in order to solve the problem of robustness or antidisturbance of the traditional PI speed controller in the permanent magnet synchronous motor. A fuzzy PI speed controller based on load torque feedback compensation is proposed for the permanent magnet synchronous motor. The combination of fuzzy PI control strategy and load feedback compensation method can enhance the robustness and disturbance rejection of the speed loop. According to the validated results of simulation and experiments, by using this PMSM speed controller, the robustness of the system speed control was enhanced markedly, and the capacity of antidisturbance was also improved significantly.
\end{abstract}

Keywords-permanent magnet synchronous motor(PMSM); Fuzzy PI; torque feedback compensation; anti-disturbance

\section{INTRODUCTION}

In recent years, with the rapid development of highperformance permanent magnet materials technology, power electronics, microelectronics technology, vector control theory and automatic control theory, the permanent magnet synchronous motor control system has been developing rapidly. Due to its superior speed performance, it has overcome a series of restrictions DC servo motor mechanical commutator and some problems for the brushes. There are many advantages such as simple structure, reliable operation; and light weight, small size, high efficiency, small moment of inertia, overload strong, and power factor and so on, so it widely used in the field of high-precision, high-performance servo control, robotics.[1-2]

As the motor running in the actual process, there will be some changes in inertia or load changes cases, which likely to affect the system control performance. The servo control itself requires no output overshoot and quickly track the input command, which can hold the state steady and no static error at the same time. Therefore, the motor system needs to have a relatively strong robustness and disturbance rejection for parameter changes. To solve this problem, many researchers have proposed different control schemes, there are adaptive control ${ }^{[3-5]}$, fuzzy control ${ }^{[6-7]}$ and the sliding mode control scheme ${ }^{[8-9]}$ to design a speed controller of the permanent magnet synchronous motors. Also, a variety of speed, torque observer and inertia identification method is also widely used in these schemes. The literature [6-7] analyzed the fuzzy PI speed controller in the permanent magnet synchronous motor and demonstrates it can enhance the robustness of speed control.

In this paper, a fuzzy PI speed controller which is based on the load torque feedback compensation scheme is presented. The fuzzy PI control enables online self-tuning, so that the same conditions, the system more robust. Meanwhile fuzzy PI speed controller and PI speed controller have a same transfer function for speed changes caused by the disturbance, so they have the same anti-disturbance capability. Therefore the load torque feedback compensation strategy can adaptively compensate for the speed disturbance and increase the speed loop the disturbance rejection.

\section{MATHEMATICAL MODELLING OF PMSM}

Assuming PMSM stator winding is sinusoidal waveform of electromotive force, the gap is a positive sinusoidal magnetic field, ignoring the core saturation effects, excluding the eddy current and hysteresis losses, and while the permanent magnet and rotor without no damping effect, in the $\mathrm{d}-\mathrm{q}$ coordinate system PMSM voltage equation is:

$\left\{\begin{array}{l}u_{d}=L_{d} d i_{d} / d t-\omega_{e} L_{q} i_{q}+R_{s} i_{d} \\ u_{q}=L_{q} d i_{q} / d t+\omega_{e} L_{d} i_{d}+\omega_{e} \psi_{f}+R_{s} i_{q}\end{array}\right.$

Flux equation:

$\left\{\begin{array}{l}\psi_{d}=L_{d} i_{d}+\psi_{f} \\ \psi_{q}=L_{q} i_{q}\end{array}\right.$

Mechanical equation:

$J d \omega / d t=T_{e}-B \omega-T_{L}$

Electromagnetic torque equation:

$T_{e}=3 P \psi_{f} i_{q} / 2=K_{T} i_{q}$

where: $u_{d}, u_{q}, \psi_{d}, \psi_{q}, i_{d}, i_{q}$ are voltage, flux and current at d-q axis. $\omega_{\mathrm{e}}, R_{\mathrm{s}}, \psi_{f}, \omega 、 J 、 T_{\mathrm{e}}, B$

$T_{\mathrm{L}} 、 P$ are Electrical angular speed, the stator resistance, 
magnetic flux, moment of inertia, the electromagnetic torque, friction coefficient, the load torque and the number of pole pairs.

\section{FUZZY PI SPEED CONTROLLER BASED ON LOAD TORQUE FEEDBACK COMPENSATION STRATEGY}

The literature [4] showed that it can improve system speed disturbance rejection control by the load torque compensation, reduce the oscillation amplitude perturbations for speed. The literature ${ }^{[7]}$ showed that the fuzzy PI speed controller can effectively enhance the robustness of the speed control, such as the problem of motor just started speed overshoot in the case can be reduced. In this paper, it combine the fuzzy PI and feedback compensation control for load torque, make it have a certain anti-disturbance capability, and enhance the robustness of the system speed control.

\section{A. Feedback Compensation Control Strategy}

In actual conditions, the disturbance reflected some load torque fluctuations. Therefore, the observed torque value use for feed forward compensation, in order to reduce volatility, thereby improving disturbance rejection. Block diagram of the control strategy as shown in Fig.1, using the load torque feedback compensation strategy to enhance the antidisturbance capacity of the system speed loop. The control system block diagram as shown in Fig.2.

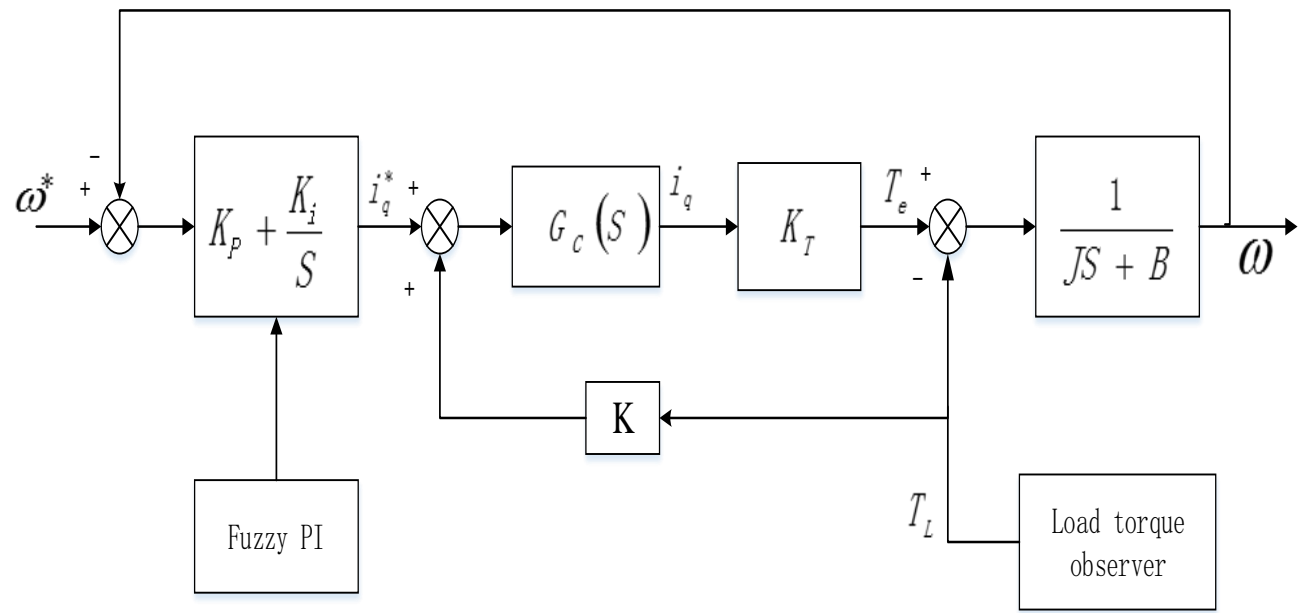

Fig. 1. Fuzzy PI speed controller with load torque feedback compensation

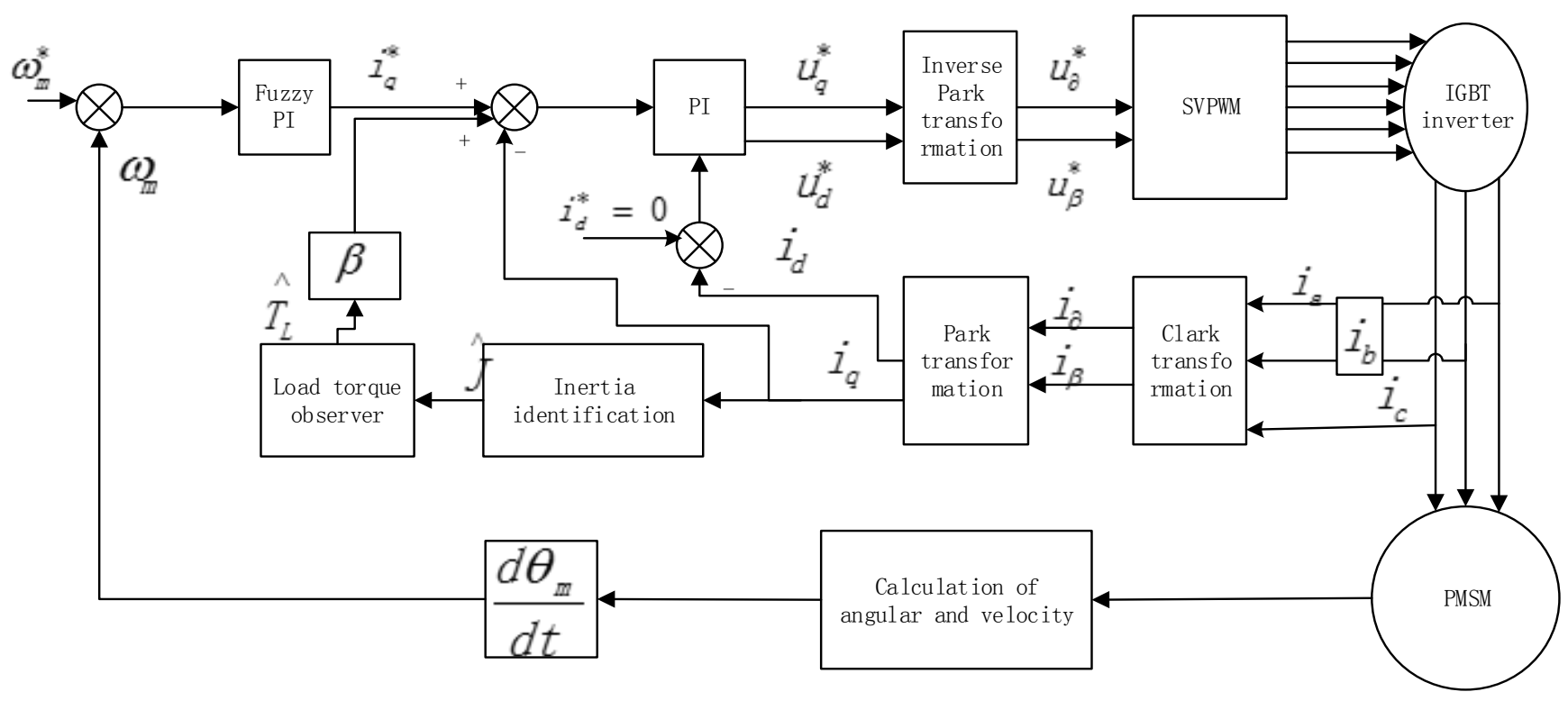

Fig. 2. Fuzzy PI control system based on feedback compensation 


\section{B. Load Reduced Order Observer}

In this paper, a load reduced order observer is used ${ }^{[10]}$, it can real time observe load torque changes to achieve feedback compensation strategies.

Since the change time of the load torque is much less than the sampling frequency of the system controller, it is generally believed the load torque does not substantially change in the control cycle, namely:

$d T_{L} / d t=0$

Then according to equation (3) and (6), the state equation can be obtained:

$\left\{\begin{array}{l}d x / d t=A x+B u \\ y=C x\end{array}\right.$

There: $A=\left[\begin{array}{cc}-B / J & -1 / J \\ 0 & 0\end{array}\right] ; \quad B=\left[\begin{array}{c}1 / J \\ 0\end{array}\right] ; \quad X=\left[\begin{array}{c}\omega \\ T_{L}\end{array}\right]$;

$C=[1 \quad 0] ; u=T_{e} ; \quad y=\omega_{\mathrm{e}}$.

That system input variables for the motor electromagnetic torque, the state variables for the load torque and mechanical acceleration, the output variable is the mechanical angular velocity. Reduced-order state observer model, the following equation (7):

$\left\{\begin{array}{l}\hat{d} \hat{x} / d t=A \hat{x}+B u+K(y-\hat{y}) \\ \hat{y}=C \hat{x}\end{array}\right.$

There: $\hat{x}=\left[\begin{array}{cc}\wedge & \wedge \\ T_{L}\end{array}\right]^{T}$ for the estimated state variables; $K=\left[\begin{array}{ll}k_{1} & k_{2}\end{array}\right]^{T}$ for State feedback gain matrix.

That can be obtained from the above formulas, equations of state motor:

$$
\begin{aligned}
& \left\{\hat{d \omega} / d t=(-B / J) \hat{\omega}+T_{e} / J-T_{L} / J+k_{1}(\omega-\hat{\omega})\right. \\
& d \hat{T_{L}} / d t=k_{2}(\omega-\hat{\omega})
\end{aligned}
$$

That is according to formula (8), designing a load torque observer, the schematic diagram of the load torque observer as shown in Fig. 3.

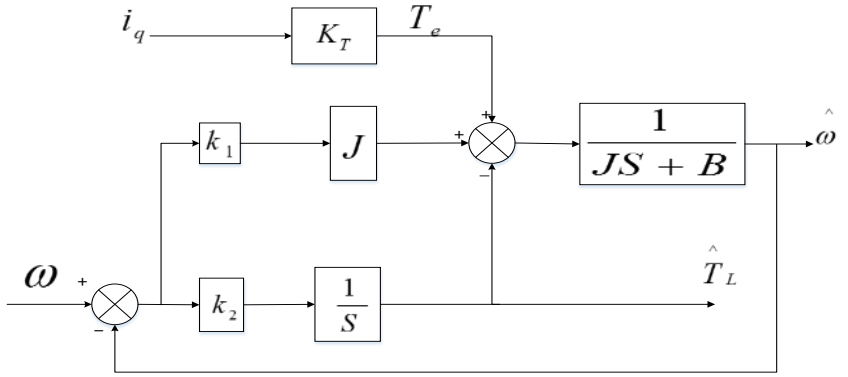

Fig. 3. The load torque observer

C. Fuzzy PI Speed Controller Analysis and Design

Speed control system block diagram as shown in Fig.4:

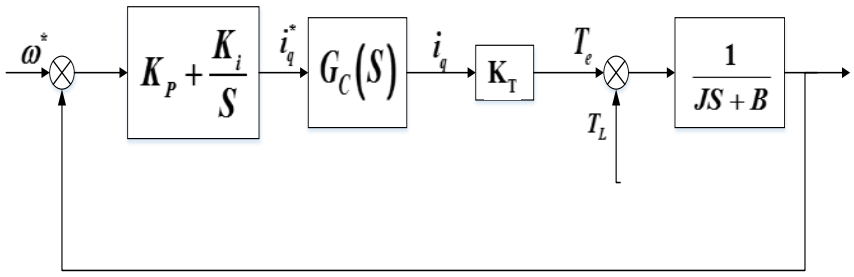

Fig. 4. Speed control system block diagram (PI controllers)

Transfer function of PI speed controller $G_{S}(S)$ are

$G_{S}(S)=K_{P}+\frac{K_{i}}{S}$

There $K_{P} 、 K_{i}$ are proportional gain and integral gain coefficient.

Traditional PI control parameters of the speed controller is typically pre-set and remain unchanged during operation, and the fuzzy PI control is that two output of fuzzy controller are as the proportional, integral coefficient, adjust the controller parameters in real time according to the working conditions to achieve better control, control block diagram as shown in Fig.5.

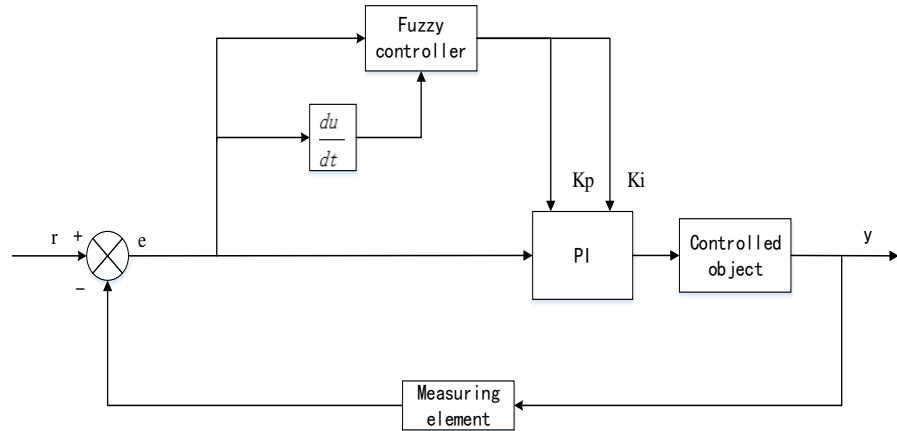

Fig. 5. Fuzzy PI controller 
In this paper, fuzzy PI speed controller for PMSM speed deviation e and error change ec, adjusted in accordance with the fuzzy control rules, the amount of blur after processing the output $\mathrm{Kp}, \mathrm{Ki}$, in order to achieve real-time online PI parameter adjustment.

Fuzzy control core design is based on engineering and technical personnel technical knowledge and practical experience, establish appropriate fuzzy rule table. According to the fuzzy control table, Kp, Ki parameters were tuning. e,ec $=\{-$ $3,-2,-1,0,1,2,3\}, \quad$ Its fuzzy subset, $\mathrm{e}, \mathrm{ec}=\{\mathrm{NB}, \mathrm{NM}, \mathrm{NS}, \mathrm{Z} 0, \mathrm{PS}, \mathrm{PM}, \mathrm{PB}\}$, where elec $\mathrm{Kp} 、 \mathrm{Ki}$ are normally distributed, Whereby each fuzzy subset membership is obtained, And in accordance with the membership table of each fuzzy subset and fuzzy control model of the parameters, using fuzzy synthesis to design fuzzy matrix of PI parameters, which make control system complete PI parameters tuning online by being analysis, looking up and operating the result of fuzzy logic rules.

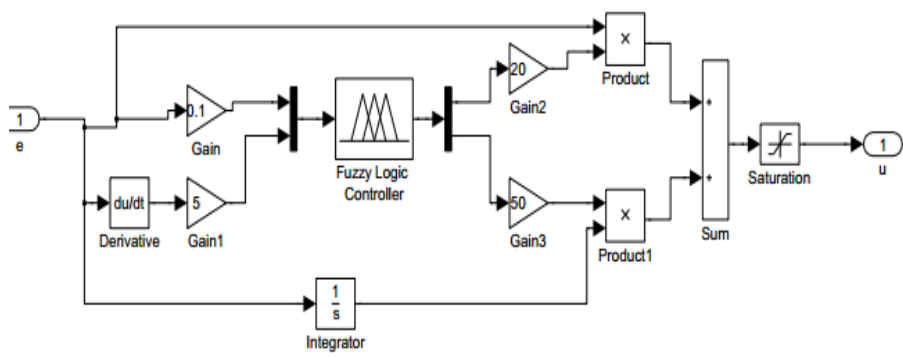

Fig. 6. Fuzzy PI speed controller emulation module

\section{Simulation AND EXPERIMENTAL RESUltS}

\section{A. Simulation Results}

To verify the performance of fuzzy control PI speed controller for PMSM, using Matlab / Simulink control system to achieve a digital simulation, Fuzzy PI speed controller based on load torque feedback compensation for PMSM control system as shown in Fig.7.

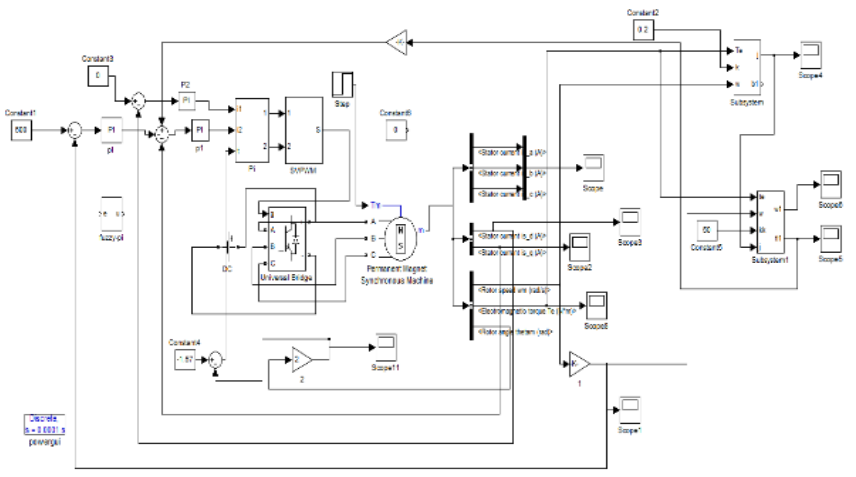

Fig. 7. PMSM simulation system diagram

PMSM parameters are as follows: $1.1 \mathrm{kw} 、 220 \mathrm{v}$ 、 $\mathrm{Ld}=\mathrm{Lq}=8.5 \mathrm{mH}, \mathrm{R}=2.875 \Omega, \psi=0.175 \mathrm{~Wb}, \mathrm{P}=4$. The motor first run at $500 \mathrm{r} / \mathrm{min}$, at $\mathrm{t}=0.1 \mathrm{~s}$, load torque suddenly add $10 \mathrm{~N}$ - $\mathrm{m}$ to $20 \mathrm{~N} \cdot \mathrm{m}$, Speed estimation simulation waveforms as shown in Fig.8. As shown speed waveforms in Fig.8, Speed estimates can be a good track real speed. The jitter of load torque feedback compensation waveform than uncompensated waveform's is smaller, which indicates that the system have better anti-disturbance performance.

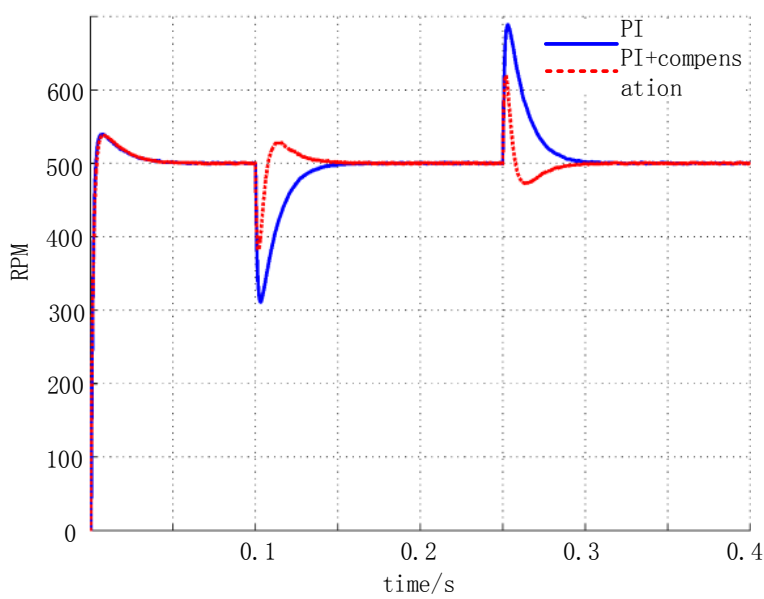

Fig. 8. Sudden increase in load speed estimation simulation waveforms

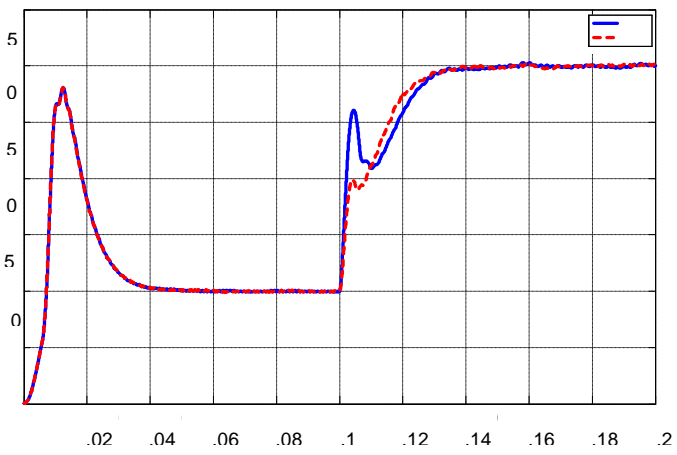

Fig. 9. Sudden increase in load torque estimation simulation waveforms

During the time $[0-0.1 \mathrm{~s}]$ load torque is $10 \mathrm{~N} \cdot \mathrm{m}$, during the time [01-0.2s] load torque is $30 \mathrm{~N} \cdot \mathrm{m}$. Speed fluctuation of fuzzy PI speed controller is small. When the disturbances occur, the oscillation amplitude is less than PI speed controller, which verify the fuzzy PI speed controller have more robustness than traditional PI controller.

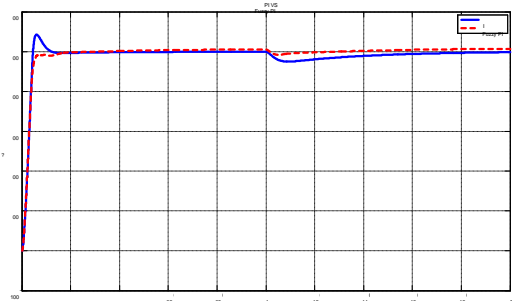

Fig. 10. Speed estimation simulation waveforms

Figures 11 is the torque estimation and speed estimation waveforms for given a rectangular wave command torque 0 and $20 \mathrm{~N} \cdot \mathrm{m}$., Period of $0.2 \mathrm{~s}$, running $800 \mathrm{r} / \mathrm{min}$ speed. 


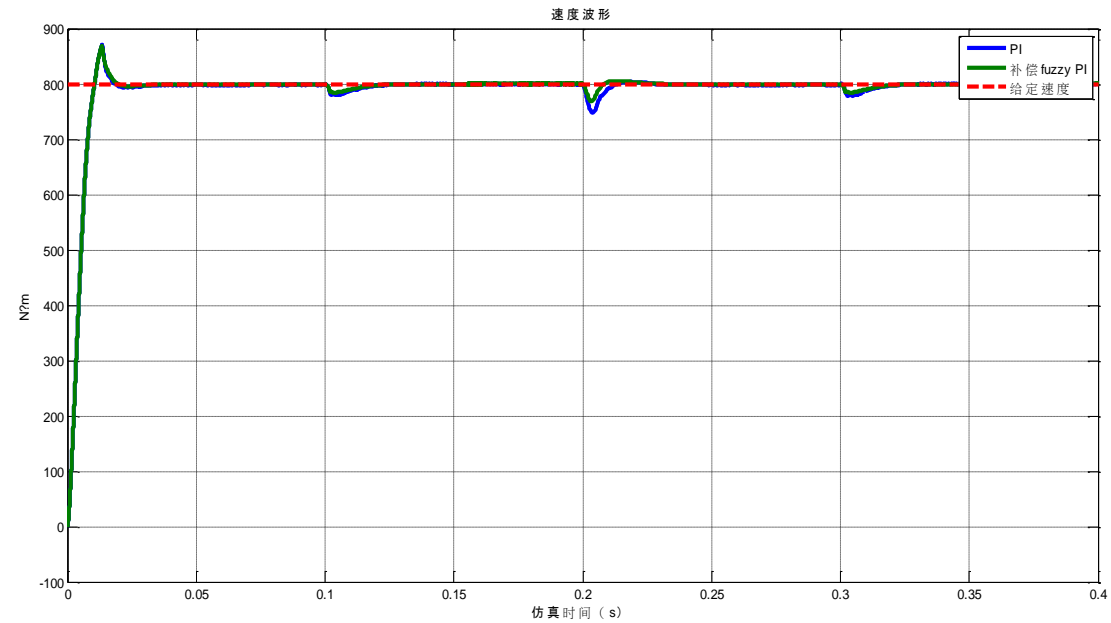

Fig. 11. Speed estimation simulation waveforms

Speed oscillation amplitude of PI speed controller is 50r / min, while Speed oscillation amplitude of the fuzzy PI speed controller speed is $25 \mathrm{r} / \mathrm{min}$. which indicates that the system have better anti-disturbance performance.

\section{B. Experimental Results}

In this paper, in order to verify the effectiveness of the control strategy, which was tested in adjustable load experimental platform, and by controlling the excitation power to achieve its load changes. At low speed 300 / min, it suddenly increase and decrease $5 \mathrm{~N} \cdot \mathrm{m}$ load. There are some experimental waveforms, they are mechanical angular speed and the phase current waveforms for the traditional PI controller without feedback compensation and fuzzy PI controller with feedback compensation. Fuzzy PI controller combine with torque feedback compensation strategy, which play a role in the inhibition of the dynamic response of the speed overshoot, improving system anti-disturbance performance.
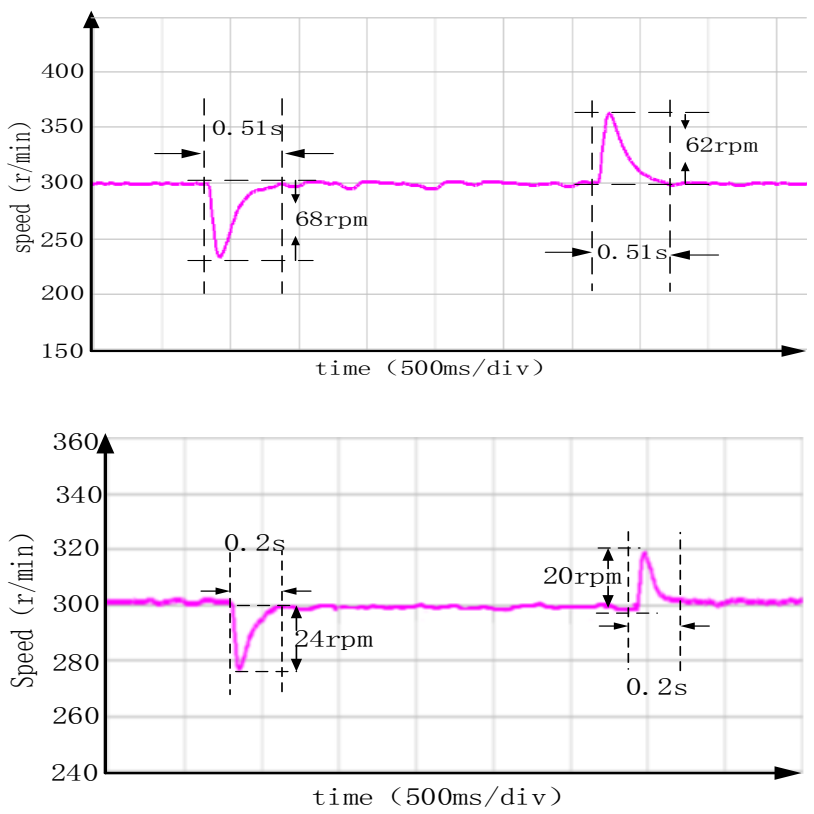
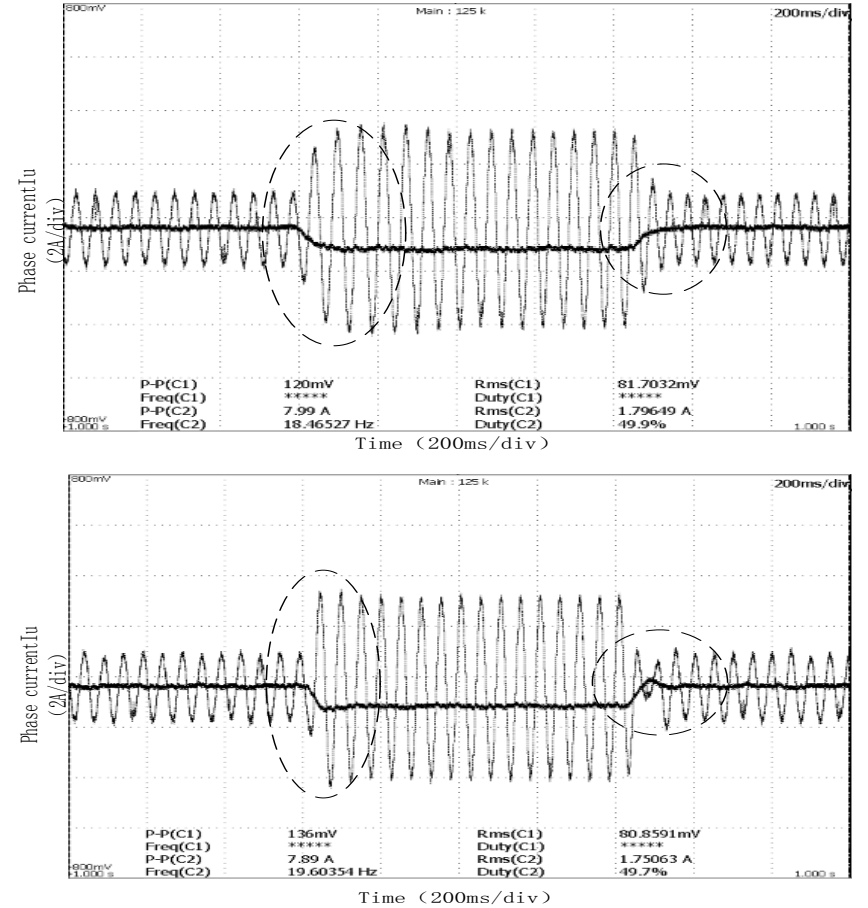

Fig. 12. at 300r / min, a sudden increase and a sudden reduction of the experimental results

\section{CONCLUSION}

In this paper, in order to solve the robustness, antidisturbance ability and other issues of traditional PI speed controller for PMSM, a fuzzy PI control scheme based on load torque feedback compensation is proposed, which can improve system speed loop disturbance rejection performance and robustness of the system speed control.

Simulation results and experiment results show that using this control scheme that can significantly reduce the speed overshoot. When the load torque steps change, the speed controller significantly reduce the amplitude of the oscillation speed. Overall, the robustness and disturbance rejection capability has significantly improved. 


\section{REFERENCES}

[1] Kou Baoquan, Chen Shukang. AC servo motor and control [M]. Beijing, China Machine Press, 2008.

[2] Yuandeng Ke, Taosheng Gui AC permanent magnet motor speed control system [M] Beijing: Mechanical Industry Press, 2011.

[3] S. Bolognani, L. Sgarbossa,M . Zordan Self-tuning of MTPA current vector generation scheme in IPM Synchronous motor drives[J]. 2007 Conf. on Power Electronics and Applications : 1-10

[4] Yasser Abdel, Rady lbrahim Mohamed. Adaptive Self-Tuning Speed Control for Permanent-Magnet Synchronous Motor Drive With Dead Time[J]. 2006 Trans. On Energy Conversion Vol.21(4):855-862

[5] Xu dong, Wang Tianmiao, Jing Liumeng. Based on parameter identification of permanent magnet synchronous motors self-tuning speed control method [J] high-tech communications 2009 Vol.2:168-173

[6] Li Wenshan. Based on permanent magnet synchronous motor torque ripple PI-type iterative learning control of suppression strategy [D], Tianjin University, 2011

[7] Zhou Hui. study Based on implementation and performance fuzzy PI control of permanent magnet synchronous motor vector control system [D] Zhejiang University 2006

[8] Jia Hongping, He Yikang. PMSM Sliding Mode Direct Torque Control [J]. China Electrotechnical Society, 2006,21 (1): 1-6.
[9] Huang Lei, Cui Ying. Based on sliding mode observer of PMSM sensorless vector control $[\mathrm{J}]$. Mechanical and Electrical Engineering, 2012,29 (11): 1303-1305.

[10] Lu Wenqi, Hu Yuwen. Anti-disturbance adaptive control for permanent magnet synchronous motor servo system $[\mathrm{J}]$. Proceedings of the CSEE . 2011, 31(3): 96-101.

[11] Liu Zhigang, Li Shihua. Active disturbance rejection controller based on permanent magnetic synchronous motor model identication and compensation[J]. Proceedings of the CSEE,2008, 28(24): 118-123.

[12] Sun Kai, Xu Zhenlin, Gai Kuo. A novel position controller of PMSM servo system based on active-disturbance rejection controller[J]. Proceedings of the CSEE, 2007, 27(15): 43-46.

[13] Lai C K, Shyu K K. A novel motor drive design for incremental motion system via sliding mode control method[J]. IEEE Trans. on Industrial Electronics, 2005, 52(2) : 499-507.

[14] Landau I D. Adaptive control : The model reference approach[M]. Wu Baifan Translation. Beijing : National Defence Industry Press, 1985 : 90-95.

[15] Guo Qingding, Wang Chengyuan. AC servo system[M]. Beijing : China Machine Press, 1994 : 20-26. 